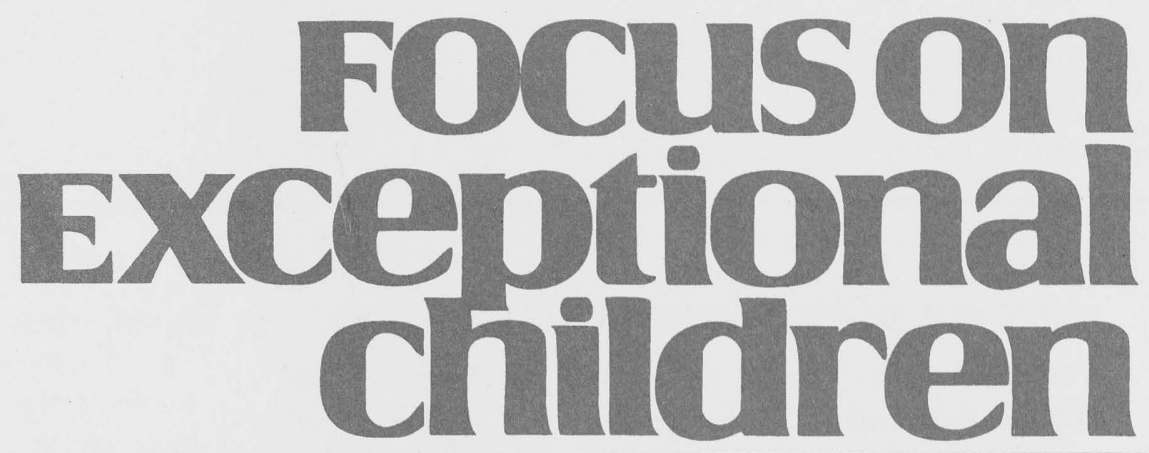

\title{
Self-Determination and Quality of Life: Implications for Special Education Services and Supports
}

\author{
Michael L. Wehmeyer and Robert L. Schalock
}

The United States is engaged in a debate concerning the efficacy of the public school system and about reforms to address the perceived inadequacies of the current system. This is not a new debate or a unique time in the history of education, for such debates ebb and flow as society's understanding of and emphasis on the purposes of education change. We say "purposes" in plural form intentionally, for despite overheated rhetoric to the opposite, the educational system has always had multiple purposes, from learning for the sake of knowledge itself to preparation for employment and citizenship (Pulliam \& Van Patten, 1995).

Currently, the debate revolves around the importance of school accountability through, primarily, standards-based reform (Sykes \& Plastrik, 1993). Although the intent of this article is not to critique this particular type of reform, there has been concern over the possible conflict between long-held beliefs about the education of students with disabilities and standards-based reform, with special attention to the extent to which testing based on state content and performance standards narrows the curriculum to only core academic content areas and limits the functionality of the curriculum for students with disabilities (Committee on Goals 2000, 1997; Committee on Appropriate Test Use, 1999; Wehmeyer, Lattin, \& Agran, in press).

Individualization is a hallmark of the federal legislation mandating the education of students with disabilities and best practice in the field. Consequently, there is considerable concern about the impact of mandates to provide access to the general curriculum on the education of these students.

We begin this article, which focuses on self-determination and quality of life in special education services and supports, with reference to these concerns for two reasons. First, we recognize that educators working with students with disabilities can no longer consider curricular and instructional content as separate from the general curriculum, whether it is the provision of transition services, the delivery of functional or occupational curriculum, or promoting self-determination to achieve a higher quality of life. Second, we want to examine the issue of promoting self-determination to enhance quality of life within the context of and as representing excellent education for all students. Our contention is that a focus on self-determination provides a means to achieve both objectives.

Dr. Wehmeyer is Associate Research Professor, Schiefelbusch Institute on Life Span Studies; Director, SelfDetermination Projects, Beach Center on Families and Disability; Department of Special Education, University of Kansas. Dr. Schalock is Professor Emeritus, Department of Psychology, Hastings College, Hastings,

Nebraska. 


\title{
OVERVIEW OF SELF-DETERMINATION
}

If teaching students to be self-sufficient citizens is an important outcome for the education system, it seems apparent that too few students with disabilities achieve this objective. Studies show that important adult outcomes, such as employment, independent living and community integration, remain unattainable by many youths with disabilities (Chadsey-Rusch, Rusch, \& O’Reilly, 1991).

One of the reasons that students with disabilities have not succeeded once they leave school is that the educational process has not prepared students with special learning needs adequately to become self-determined young people. Martin, Marshall, Maxson, and Jerman (1993) put it this way:

\begin{abstract}
If students floated in life jackets for 12 years, would they be expected to swim if the jackets were suddenly jerked away? Probably not. The situation is similar for students receiving special education services. All too often these students are not taught how to self-manage their own lives before they are thrust into the cold water of post-school reality.
\end{abstract}

An educational emphasis on promoting self-determination for students with disabilities emerged through the 1990s as a function of a federal initiative related to the then new

\section{Focuson
Exceptional children}

ISSN 0015-511X

FOCUS ON EXCEPTIONAL CHILDREN (USPS 203-360) is published monthly except June, July, and August as a service to teachers, special educators, curriculum specialists, administrators, and those concerned with the special education of exceptional children. This publication is annotated and indexed by the ERIC Clearinghouse on Handicapped and Gifted children for publication in the monthly Current Index to Journals in Education (CIJE) and the quarterly index, Exceptional Children Education Resources (ECER). The full text of Focus on Exceptional Children is also available in the electronic versions of the Education Index. It is also available in microfilm from Xerox University Microfilms, Ann Arbor, MI. Subscription rates: Individual, $\$ 30$ per year; institutions, $\$ 40$ per year. Copyright (C) 2001, Love Publishing Company. All rights reserved. Reproduction in whole or part without written permission is prohibited. Printed in the United States of America. Periodical postage is paid at Denver, Colorado. POSTMASTER: Send address changes to:

Love Publishing Company

Executive and Editorial Office

P.O. Box 22353

Denver, Colorado 80222

Telephone (303) 221-7333

Karen Harris

University of Maryland
Thomas Skrtic

University of Kansas

James Shriner

University of Illinois

Erica J. Lawrence Editor
Stanley F. Love Publisher federal mandates regarding provision of transition services for adolescents with disabilities (Ward, 1996; Ward \& Kohler, 1996; Wehmeyer, 1998) and requiring active student involvement in educational planning and decision making (Morningstar, Kleinhammer-Tramill, \& Lattin, 1999; Wehmeyer \& Sands, 1998). As a result of this federal focus, numerous instructional and assessment methods, materials, and strategies now are available to enable teachers to promote student self-determination (Field, Martin, Milller, Ward, \& Wehmeyer, 1998; Wehmeyer, Agran, \& Hughes, 1998). Moreover, research (Agran, Snow, \& Swaner, 1999; Wehmeyer, Agran, \& Hughes, 2000) indicates that teachers working with students who have disabilities acknowledge the importance of promoting self-determination for students with disabilities, although that acknowledgement does not always translate directly to instructional opportunities for students (Wehmeyer \& Schwartz, 1998; Wehmeyer et al., 2000).

\section{Self-Determination as an Educational Outcome}

Over the last decade, self-determination has emerged as an important construct in the education of students with disabilities. As a result of federally funded initiatives to define and describe self-determination as an educational outcome (Ward \& Kohler, 1996), a number of conceptualizations of selfdetermination to address educational needs have been formulated (see Field, 1996). Martin and Marshall (1995) summarized the "evolving definition of self-determination in the special education literature" as describing individuals who

\footnotetext{
know how to choose-they know what they want and how to get it. From an awareness of personal needs, selfdetermined individuals choose goals, then doggedly pursue them. This involves asserting an individual's presence, making his or her needs known, evaluating progress toward meeting goals, adjusting performance and creating unique approaches to solve problems. (p. 147)
}

As illustrated by this description, the actions of selfdetermined people enable them to fulfill roles typically associated with adulthood. We have forwarded a definitional framework in which self-determination refers to "acting as the primary causal agent in one's life and making choices and decisions regarding one's quality of life free from undue external influence or interference" (Wehmeyer, 1996, p. 24). According to the American Heritage Dictionary of the English Language an agent is "someone who acts or has the power or authority to act" or a "means by which something is done or caused." A causal agent, then, is someone who makes or causes things to happen in his or her life.

Within this framework, self-determined behavior refers to actions identified by four essential characteristics:

1. The person acted autonomously.

2. The action(s) was self-regulated. 
3. The person initiated and responded to the event(s) in a "psychologically empowered" manner.

4. The person acted in a self-realizing manner.

These essential characteristics emerge as children, youth, and adults develop and acquire a set of component elements of self-determination. Intervention focuses on the level of component elements.

\section{Essential Characteristics of Self-Determined Behavior}

The term essential characteristic means that an individual's actions must reflect, to some degree, each of the four characteristics identified. Age, opportunity, capacity, and circumstances can impact the extent to which any of the essential characteristics are present and, as such, the relative self-determination an individual expresses will likely vary, sometimes over time and other times across environments. Nonetheless, these essential elements have to be present. Each characteristic is a necessary but not sufficient element of self-determined behavior.

\section{Behavioral Autonomy}

Sigafoos, Feinstein, Damond and Reiss (1988) stated that "human development involves a progression from dependence on others for care and guidance to self-care and selfdirection" (p. 432). The outcome of this progression is autonomous functioning or, when describing the actions of individuals achieving this outcome, behavioral autonomy. For the purposes of the definitional framework, a behavior is autonomous if the person acts (a) according to his or her own preferences, interests, and/or abilities, and (b) independently, free from undue external influence or interference.

Autonomous behavior should not be confused with selfcentered or selfish behavior. Although humans often act according to personal interests, on some occasions a person must act in ways that do not reflect specific interests. As such, one's preference may be to act in a manner that does not directly reflect a specific interest if that is prudent or useful. Likewise, most people cannot be viewed as strictly acting alone, with no external influences. The field of disability recognizes interdependence as a desirable outcome because all people are influenced daily by others, from family members to strangers. Contextual, cultural, and social variables will define for each person an "acceptable" level of interference and influence.

\section{Self-regulated Behavior}

Whitman (1990) defined self-regulation as

a complex response system that enables individuals to examine their environments and their repertoires of responses for coping with those environments to make decisions about how to act, to act, to evaluate the desirability of the outcomes of the action, and to revise their plans as necessary. (p. 347)
Self-regulated behaviors include self-management strategies (including self-monitoring, self-instruction, self-evaluation, and self-reinforcement), goal-setting and attainment behaviors, problem-solving behaviors, and observational learning strategies. These enable students to become the causal agent in their lives (Agran, 1997).

\section{Acting in a Psychologically Empowered Manner}

Psychological empowerment is a term referring to the multiple dimensions of perceived control, including its cognitive (personal efficacy), personality (locus of control) and motivational domains (Zimmerman, 1990). Essentially, people acting in a psychologically empowered manner do so on the basis of beliefs that they (a) have control over circumstances important to them (internal locus of control), (b) possess the skills necessary to achieve desired outcomes (selfefficacy), and (c) expect the identified outcomes to result if they choose to apply those skills (outcome expectations).

\section{Self-realization}

Finally, self-determined people are self-realizing in that they use a comprehensive, and reasonably accurate, knowledge of themselves and their strengths and limitations and act to capitalize on this knowledge. This self-knowledge and understanding forms through experience with and interpretation of one's environment and is influenced by evaluations of significant others, reinforcement, and attributions of one's own behavior.

\section{Empirical Validation of the Framework}

To test this definitional framework, Wehmeyer, Kelchner, and Richards $(1995,1996)$ conducted a study of adults with mental retardation to determine their relative selfdetermination status and the relationship between this status and the hypothesized essential elements (autonomy, selfregulation, perceptions of psychological empowerment, and self-knowledge/realization). Interviews with 408 adults with mental retardation yielded responses to a survey instrument constructed to identify the degree to which individuals acted in a self-determined manner. Respondents were assigned to one of two groups, high self-determination or low self-determination, based on these responses.

This survey instrument (described in Wehmeyer et al., 1995) required that participants respond to a series of questions exploring the individuals' behaviors in six principal domains: (1) home and family living; (2) employment; (3) recreation and leisure; (4) transportation; (5) money management; and (6) personal/leadership. Questions were selected to reflect the amount of choice and control individuals had in each of these areas or the degree to which the individual acted in a manner reflecting self-determination. 
Participants also completed a series of assessments designed to determine their autonomy, self-regulation, psychological empowerment and self-realization (see Wehmeyer et al., 1996). Comparisons between groups based on selfdetermination status found that adults who exhibited more self-determined behaviors were significantly more autonomous (on both measures of autonomy), more effective social problem solvers, more assertive and self-aware, and held more adaptive perceptions of control, self-efficacy, and outcome expectations (Wehmeyer et al., 1996). With the exception of certain domain specific self-concepts, there were significant differences between groups in all areas related to the definitional framework.

\section{Component Elements of Self-Determined Behavior}

The essential characteristics that define self-determined behavior emerge through the development and acquisition of multiple, interrelated component elements, including the following.

- Choice-making skills

- Decision-making skills

- Problem-solving skills

- Goal-setting and attainment skills

- Independence, risk-taking and safety skills

- Self-observation, evaluation and reinforcement skills

- Self-instruction skills

- Self-advocacy and leadership skills

- Internal locus of control

- Positive attributions of efficacy and outcome expectancy

- Self-awareness

- Self-knowledge

Although not intended as an exhaustive list, these component elements are especially important to the emergence of selfdetermined behavior. Each of these component elements has a unique developmental course or is acquired through specific learning experiences (Doll, Sands, Wehmeyer, \& Palmer, 1996). The development and acquisition of these component elements is lifelong and begins early in life. Some elements have more applicability for secondary education instruction and transition, and others focus more on the elementary years. As such, promoting self-determination as an educational outcome will require a purposeful instructional program, one that coordinates learning experiences across the span of a student's educational experience.

In a subsequent section, we describe these component elements and provide suggestions for intervention for each. Prior to addressing instructional issues, however, we want to provide an overview of the quality-of-life construct, and particularly its use in the field of special education.

\section{OVERVIEW OF QUALITY OF LIFE}

The concept of quality of life has risen to the fore in the field of special education for a number of reasons (Keith \& Schalock, 1994; Schalock, 1995).

1. It is a social construct that is impacting program development and service and supports delivery in special education.

2. It is being used as the criterion for assessing the effectiveness of supports and services for students with disabilities.

3. The pursuit of quality is apparent at three levels in special education services: students and their advocates desiring a life of quality, educators wanting to deliver quality products and see quality outcomes, and evaluators assessing quality outcomes.

Not insignificantly, the standards-based reform movement we discussed earlier is, at its core, a "total quality management" process focused on ensuring high-quality outcomes.

Despite its attractiveness, the quality-of-life concept is neither fully understood nor immune from potential misuse (Hatton, 1998). As the field of special education continues to embrace the concept, it is timely to reflect upon the concept and its application to special education services and supports. As Yogi Berra once stated, "The problem of not knowing where you are going is that you might end up in the wrong place." The primary purpose of this section is to provide an overview of the concept of quality of life. In a subsequent section we will discuss a number of instructional, assessment, and curricular issues in implementing the concept of quality of life for students with disabilities.

\section{Three Uses of the Concept}

Over the last two decades, the way we view people with disabilities has changed significantly. This transformed vision of what constitutes the life possibilities of people with disabilities is reflected in terms that are familiar to the reader: self-determination, inclusion, strengths and capabilities, the importance of normalized and typical environments, the provision of individualized support systems, equity, and enhanced adaptive behavior and role status. As a term and concept, quality of life captures this changing vision and currently is used in the fields of disability services and special education as:

- A sensitizing notion that gives us a sense of reference and guidance from the individual's perspective, focusing on the individual and his/her environment

- A social construct that is an overriding principle to improve and enhance an individual's perceived quality of life 
- A unifying theme that provides a systematic or organizing framework to focus on the multidimensionality of a life of quality

\section{The Core Quality-of-Life Dimensions}

There is increasing agreement that quality of life is a multidimensional concept that precludes reducing it to a single "thing" of which the person may have considerable, some, or none. Current and ongoing research in this area has identified eight core quality-of-life dimensions (Schalock, 1996a): emotional well-being, interpersonal relationships, material well-being, personal development, physical wellbeing, self-determination, social inclusion, and rights. Although the number and configuration of these core dimensions vary slightly among investigators, these eight core dimensions are based on the work of Cummins (1997), Felce (1997), Hughes and Hwang (1996), Paramenter and Donelly (1997), and Renwick and Brown (1996). In reference to these core dimensions, the emerging consensus is that each person values them differently, and the value attached to each varies across one's life.

\section{Quality-of-Life Research}

Over the last decade the research and statistical design used to study the quality-of-life concept has changed. Specifically, we have seen a significant shift from a "between" approach to a "multivariate/within" approach. Historically, quality of life was studied from a between-groups (or conditions) perspective; hence, investigators sought to find factors such as socioeconomic status and large demographic population descriptors that could discriminate between persons or countries with a high quality of life and those with a lower quality of life. This "between mentality" spilled over to early work on quality of life in subtle ways, as reflected in the attitude expressed by some that we need to have different measures or quality-of-life indices for those who are higher functioning and those who are either nonverbal or lower functioning.

Shifting to a multivariate research design has a number of advantages:

1. It allows for a focus on the correlates and predictors of a life of quality rather than comparing quality-of-life scores or status. This approach has been used to evaluate the relative contribution to one's assessed quality of life of a number of personal characteristics, objective life conditions, and provider characteristics. Across a number of studies (Schalock, Lemanowicz, Conroy \& Feinstein, 1994; Schalock \& Faulkner, 1997; Schalock, Bonham, \& Marchand, 2000) personal factors (perceived sense of dignity, health status, and adaptive behavior level), environmental variables (perceived social support, current residence, employment, and integrated activities), and provider characteristics (worker stress and job satisfaction) are significant predictors of a person's assessed quality of life.

2. Once these significant predictors are identified, programmatic changes can be made to enhance the person's perceived quality of life through techniques such as personal development and wellness training, quality enhancement techniques, and quality management techniques (Schalock, 1994; Schalock \& Faulkner, 1997).

3. Multivariate research designs help us understand better the complexity of the quality-of-life concept and the role of contextual variables in the perception of a quality life.

4. Multivariate research designs shift the focus of our thinking and intervention from personal to environmental factors as major sources of quality-of-life enhancement.

\section{Quality-of-Life Assessment}

One of the most significant changes recently has been the shift toward quality-of-life-oriented, outcome-based evaluation rooted in person-referenced outcomes. This emerging focus reflects the subjective and personal nature of one's perceived quality of life, and also the quality revolution, consumer empowerment with the associated expectations that special education programs will result in an improved quality of life for students, the increased need for program outcome data that evaluate the effectiveness and efficiency of special education programs, the supports paradigm based on the premise that providing needed and relevant supports will enhance one's quality of life, and the pragmatic evaluation paradigm that emphasizes the practical, problem-solving orientation to program evaluation (Schalock, in press).

Our approach to quality-of-life assessment is based on four assumptions:

1. Quality of life is composed of the eight core dimensions listed previously.

2. Each of the eight core dimensions can be defined operationally in terms of a number of specific indicators, such as those summarized in Table 1.

3. The focus of quality-of-life assessment should be on person-referenced outcomes.

4. Assessment strategies should use either personal appraisal or functional assessment measures reflecting one or more of the eight core dimensions.

The indicators listed in Table 1 can be assessed by using either personal appraisal and/or functional assessment strategies. It should be noted that the personal appraisal strategy should be equated to the historical notion of subjective 
Table 1

Quality-of-Life-Referenced Indicators

\begin{tabular}{|c|c|c|}
\hline Dimension & Exemp & lary Indicators \\
\hline Emotional well-being & $\begin{array}{l}\text { Safety } \\
\text { Spirituality } \\
\text { Happiness }\end{array}$ & $\begin{array}{l}\text { Freedom from stress } \\
\text { Self concept } \\
\text { Contentment }\end{array}$ \\
\hline Interpersonal relations & $\begin{array}{l}\text { Intimacy } \\
\text { Affection } \\
\text { Family }\end{array}$ & $\begin{array}{l}\text { Interactions } \\
\text { Friendships } \\
\text { Supports }\end{array}$ \\
\hline Material well-being & $\begin{array}{l}\text { Ownership } \\
\text { Financial } \\
\text { Security } \\
\text { Food }\end{array}$ & $\begin{array}{l}\text { Employment } \\
\text { Possessions } \\
\text { Social economic status } \\
\text { Shelter }\end{array}$ \\
\hline Personal development & $\begin{array}{l}\text { Education } \\
\text { Skills } \\
\text { Fulfillment }\end{array}$ & $\begin{array}{l}\text { Personal competence } \\
\text { Purposeful activity } \\
\text { Advancement }\end{array}$ \\
\hline Physical well-being & $\begin{array}{l}\text { Health } \\
\text { Nutrition } \\
\text { Recreation } \\
\text { Mobility }\end{array}$ & $\begin{array}{l}\text { Health care } \\
\text { Health insurance } \\
\text { Leisure } \\
\text { Activities of daily living }\end{array}$ \\
\hline Self-determination & $\begin{array}{l}\text { Autonomy } \\
\text { Choices } \\
\text { Decisions }\end{array}$ & $\begin{array}{l}\text { Personal control } \\
\text { Self-direction } \\
\text { Personal goals/values }\end{array}$ \\
\hline Social inclusion & $\begin{array}{l}\text { Acceptance } \\
\text { Status } \\
\text { Supports } \\
\text { Roles }\end{array}$ & $\begin{array}{l}\text { Community activities } \\
\text { Work environment } \\
\text { Volunteer activities } \\
\text { Residential environment }\end{array}$ \\
\hline Rights & $\begin{array}{l}\text { Privacy } \\
\text { Voting } \\
\text { Access }\end{array}$ & $\begin{array}{l}\text { Due process } \\
\text { Ownership } \\
\text { Civic responsibilities }\end{array}$ \\
\hline
\end{tabular}

indicators and the functional assessment strategy to the historical notion of objective indicators.

\section{Personal Appraisal}

The personal appraisal strategy addresses the subjective nature of quality of life, typically asking the person how satisfied he or she is with the various facets of his or her life. For example, this is the approach we have used in the Quality of Student Life Questionnaire (Keith \& Schalock, 1995) wherein we asked questions such as, "How satisfied are you with your education situation?" and "How satisfied are you with the skills and experience you have gained or are gaining from your classes?"

Even though the person's responses are subjective, responses have to be measured in psychometrically acceptable ways. Thus, a 3- to 5-point Likert scale can be used to indicate the person's level of expressed satisfaction. The advantages of this approach to measurement are that it encompasses the most common dependent measure (satisfaction) used currently in quality-of-life assessments, it allows one to measure factors that historically have been considered to be major subjective indicators of a life of quality, and it allows one to quantify the level of expressed satisfaction.

\section{Functional Assessment}

The most typical formats used in functional assessment are rating scales, participant observation, and questionnaires. Each of these attempts to document a person's functioning across one or more core quality-of-life dimensions and the respective indicator. To accomplish this, most instruments employ some form of an ordinal rating scale to yield a profile of the individual's functioning. For example, one might ask (or observe), "How frequently do you use community recreational facilities?" or, "How many times do you go into the community to shop or eat each week?" The advantages of functional assessment are that this form of assessment is more objective and performance-based, allows for the evaluation of outcomes across groups, and thereby provides important feedback to educators and evaluators as to how they can change or improve their services and supports to enhance the student's perceived quality of life.

An advantage of using the quality-of-life assessment suggested above is that one need not use different indicators for subjective versus objective measurement; rather, the core dimensions remain constant. What varies is whether one uses a personal appraisal or a functional assessment approach to assess the respective indicator. Thus, all assessment is focused clearly on the eight core dimensions of quality of life. It is apparent that some of the domains are more amenable to personal appraisal and others to functional assessment.

For example, personal appraisal might best be used for the core dimensions of emotional well-being, self-determination, rights, and interpersonal relations; whereas functional assessment might better be used for the core dimensions of material well-being, personal development, physical well-being, and social inclusion. Hence, there is a definite need to use both personal and functional assessments to measure one's perceived quality of life.

In summary, we have made significant progress in understanding the concept of quality of life. Specifically, we are closer to understanding that:

- Quality of life is a multidimensional phenomenon whose core dimensions and their importance vary among persons and within their lifespans.

- Quality-of-life assessment should be based on core quality-of-life dimensions and their indicators, using measurement strategies that combine personal appraisal and functional assessment. 
- Multivariate research designs allow focus on the contextual nature of a life of quality.

Despite this better understanding, a number of instructional and curricular issues remain. These issues, addressed in the a subsequent section, relate primarily to implementation of quality enhancement techniques, use of positive behavior supports, and persons with disabilities assessing their own quality of life.

\section{HOW ARE QUALITY OF LIFE AND SELF-DETERMINATION RELATED?}

The focal points of this article are both self-determination and quality of life. These constructs, described separately above, are often mentioned in the same context. Yet, to our knowledge, there has been no systematic treatment or exploration of the relationship between these areas. Nevertheless (and not coincidentally), the theoretical frameworks of both self-determination and quality of life, described previously, rely on or reference each construct as a means of defining the other. In considering the relationship between them and their implications for special education supports and services, we would return to the premise introduced at the beginning of the article. Stated in terms of related theoretical statements, the relationship and importance of these constructs to the education of students with disabilities include the following.

1. It is generally accepted (and, as discussed subsequently, there is empirical evidence) that one factor contributing to positive outcomes in the lives of students with disabilities is enhanced self-determination (Wehmeyer \& Schwartz, 1997).

2. People who are self-determined make or cause things to happen in their lives; they are causal agents in their lives. Causal agency, however, implies more than simply making something happen; it implies that the individual who makes or causes that thing to happen does so to accomplish a specific end. Intuitively, and by definition, these ends or changes are designed to improve or enhance the person's quality of life.

3. The extent to which a person is self-determined either influences or is influenced by other core dimensions of quality of life and, in combination with these other core dimensions, influences or impacts global or overall quality-of-life status.

These statements are important only if some value is placed on quality of life as an outcome relevant to the field of special education. The most visible sense of "outcomes" important to special education are contained in the IDEA's transition services mandates requiring that students with disabilities be provided transition services that are outcomes-oriented. In the early years of special education, this outcomes-orientation focused almost exclusively on one outcome - employment. Within a short time, however, it was generally accepted that these programs and services should prepare students to attain a wide variety of adult outcomes (Halpern, 1985; Sitlington, 1996).

This broader mandate was codified in the 1990 amendments to IDEA and reaffirmed in the 1997 amendments, in which transition services were defined as "a coordinated set of activities for a student, designed within an outcomeoriented process which promotes movement from school to post school activities" [Sec. 602(a)(19)]. Post-school activities were broadly defined to include post-secondary education, vocational training, integrated and supported employment, continuing and adult education, adult services, independent living, and community participation.

Halpern (1993) elaborated upon this broader mandate in the 1990 amendments to IDEA, suggesting that, although the statutory language did not use the term "quality of life," the mandate clearly defined the multidimensional expression and validity of a variety of life goals. He further suggested that the next logical step in defining and evaluating the utility of transition services was to use "quality of life" as a conceptual framework for structuring and examining transition outcomes.

Although this suggestion seemed persuasive from both theoretical and historical perspectives, there has not been an overwhelming surge of effort to make transition programs accountable from a quality-of-life conceptual framework. Instead, special education remains largely reliant on process indicators of quality (e.g., compliance with regulations in the IDEA for what should be in the IEP), and for some basic outcome indicators, such as job and residential placements.

The standards-based school reform movement has introduced a different set of accountability indicators, primarily tests tied to the curriculum, which in turn are tied to state or local educational standards. In some states this testing is high stakes-meaning that the consequences are significant for students, teachers, and/or administrators if students do not show progress on the tests.

Both the process form of accountability inherent in the IDEA (e.g., compliance with regulations pertaining to the IEP) and the accountability system within the standardsbased reform movement have an underlying assumption that adherence to the accountability indicators will improve the educational experience and, presumably, improve student outcomes. Indeed, even the "outcomes" listed in the transition services mandates in IDEA are there based on an assumption that, by achieving such outcomes, students will attain a better quality of life. 
These assumptions, however, are just that-assumptions. Certainly a good job is one factor contributing to a better quality of life because it provides income for financial wellbeing, health insurance for physical well-being, opportunities for social relationships, and so forth. Likewise, one can suggest that, by listing what should be in a student's IEPwhich, theoretically, should contribute to a better educational program - or by holding students or educators accountable for student progress on tests designed to measure attainment of high standards for educational outcomes, one can improve education and, in turn, improve a student's quality of life as an adult. The problem is that these assumptions may or may not be true. As Halpern (1985) noted, getting a job is not a prima facia guarantee of the good life. None of these accountability mechanisms adequately ensures that education leads to a better quality of life, because they simply don't measure that specific outcome.

The difficulty in measuring such outcomes is well documented, but examples in other fields point out instances in which accountability measures were transformed from mainly process indicators to person-centered outcome indicators. For example, in the field of residential services for people with mental retardation, accountability and accreditation traditionally have been based on an agency's compliance with organizational procedures and paperwork regulations.

In 1997, however, the Council on Quality and Leadership in Supports for People with Disabilities, an agency that accredits residential service providers, published a series of personal outcome measures it was using to hold agencies accountable for outcomes that related to quality of life. Some of the "indicators" the Council used to measure quality in service delivery and to accredit high-quality programs included whether people choose personal goals, choose where and with whom they live, are satisfied with their services, choose their daily routine, participate in the life of the community, and exercise their rights.

As the field of special education endorses the importance of promoting self-determination as a valued outcome of a student's educational process, it becomes both an opportunity and an obligation that the field also begin to focus attention more on quality of life. An emphasis on promoting student self-determination is, in essence, a commitment to enable young people to set their own goals to achieve outcomes they value. Those outcomes will vary a great deal according to personal preferences, interests, abilities, and opportunities.

Therefore, it becomes incumbent upon us to move from the complacency of job placement as an outcome for which we are accountable, to enabling young people to move into post-secondary employment circumstances that result in a higher quality of life. In essence, if we are serious about promoting self-determination, we have to become more serious about examining quality of life as an organizing theme to examine personal outcomes. Of course, this call to action is relevant only if promoting self-determination is, indeed, an important educational objective.

\section{ARE SELF-DETERMINATION AND QUALITY OF LIFE IMPORTANT FOR STUDENTS WITH DISABILITIES?}

Quality of life is a construct that attempts to conceptualize what "living the good life" means, and, as such, is almost by default a potentially important outcome on which to focus. The question that perhaps is more important is whether promoting self-determination is worth the time and effort involved. The proposition that self-determination is an important educational outcome presumes that self-determination and positive adult outcomes are causally linked.

Although such a link seems intuitively obvious, until recently, limited empirical evidence has examined this assumption. Instead, the link between self-determination and positive adult outcomes for youth with disabilities was established by examining the contributions of the component elements, such as goal-setting and problem solving, to more favorable adult outcomes. In deference to space limitations, we will not overview that literature in detail, but generally the opportunity to make choices, express preferences, set goals, and self-regulate learning and behavior all have been linked to more favorable educational and adult outcomes (see Wehmeyer, Agran, \& Hughes, 1998, for overview of this literature).

Research on the component elements of self-determined behavior provides only indirect evidence that youth who are more self-determined achieve more positive adult outcomes. Wehmeyer and Schwartz (1997) measured the selfdetermination of 80 youth with cognitive disabilities (mild mental retardation or learning disability). One year after these students left high school, they and their families were contacted to determine status in several areas, including student living arrangements, current and past employment situations, post-secondary education status, and community integration outcomes.

This information was analyzed, controlling for level of intelligence and type of disability. The data showed a consistent trend in which self-determined youth were doing better than their peers one year out of school. Members of the high self-determination group were more likely to have expressed a preference to live outside the family home, have a savings or checking account, and be employed for pay. Of the high-self-determination group, $80 \%$ worked for pay one year after graduation, whereas only $43 \%$ of the low-selfdetermination group did likewise. Among school-leavers who were employed, youth who were in the self-determined group earned significantly more per hour $($ Mean $=\$ 4.26)$ 
than their peers in the low-self-determination group (Mean $=\$ 1.93$ ).

If promoting self-determination has positive benefits for students, as the Wehmeyer and Schwartz (1997) study suggests, the next question of merit is whether there is empirical evidence of the link between self-determination and quality of life. We discussed in the previous section the theoretical linkages, but is there evidence to bolster those hypothetical links? Wehmeyer and Schwartz (1998b) empirically examined the link between self-determination and quality of life for 50 adults with mental retardation living in group homes. Controlling for level of intelligence and environmental factors contributing to a higher quality of life, we found that self-determination predicted group membership based on quality of life scores. That is, a person's relative selfdetermination was a strong predictor of his or her quality of life; people who were highly self-determined had a higher quality of life, and people who lacked self-determination had a less positive quality of life.

More research is needed to examine the impact of selfdetermination on positive adult outcomes, including quality of life. Nevertheless, the limited direct evidence and the preponderance of evidence from examination of the impact of component elements of self-determined behavior on positive educational, achievement, and adult outcomes suggests that self-determination is, indeed, an important focus for educators.

\section{INSTRUCTIONAL, ASSESSMENT, AND CURRICULAR ISSUES IN SELF-DETERMINATION}

Given that self-determination is an important educational outcome, what can educators do to enable students to achieve this outcome? As a result of the federal initiatives of the past decade (Ward \& Kohler, 1996), a number of curricular and assessment materials have been designed to promote self-determination for youth with disabilities (see Field et al., 1998; Wehmeyer et al., 1998). In addition, instructional programs are available which enable students with disabilities to become meaningful participants in the educational planning process (see Wehmeyer \& Sands, 1998).

The theoretical framework of self-determination described earlier suggests that self-determination emerges as students develop or acquire a set of component elements of selfdetermined behavior. Efforts to enhance these component elements take three primary tracks:

1. Instruction to promote capacity (skills and knowledge)

2. Opportunities to experience control and choice

3. The design of supports and accommodations.

The primary role of education in this process is in promoting capacity, although this does not mitigate the importance of providing opportunity and identifying supports and accommodations. These capacity-enhancement efforts can be driven by the curricular or other materials discussed earlier, or through instruction on each specific component element. Next we will examine issues related to the latter and offer suggestions for promoting each component. We note at the outset that this involves educational efforts across a student's educational experience, from preschool and elementary grades through secondary and post-secondary education.

\section{Teaching Component Elements of Self-Determination}

\section{Choice-Making}

Perhaps more emphasis has been placed on the choicemaking component as critical to a positive quality of life for people with disabilities than most of the other elements combined. Making a choice is, quite simply, communicating a preference, and instruction in making choices focuses on one or both of these elements-either identifying a preference or communicating that preference. Except in unique circumstances, there usually is no need to "teach" choicemaking, per se, although there may be a need to enable or teach children who have problems communicating new, alternative, or even more appropriate ways to indicate their preferences. By and large, educational efforts should be aimed at using choice-making opportunities to provide experiences of control, and to teach students that not all options are available to them and that choice options are constrained for all people.

Shevin and Klein (1984, p. 164) emphasized the importance of integrating choice-making opportunities throughout the school day and listed five keys to maintaining a balance between student choice and professional responsibility:

1. Incorporating student choice as an early step in the instructional process

2. Increasing the number of choices related to a given activity which the student makes

3. Increasing the number of domains in which decisions are made; and raising the significance in terms of risk and long-term consequences of the choices that the student makes

4. Clear communication with the student concerning areas of possible choice, and the limits within which choices can be made.

Similarly, Brown, Appel, Corsi, and Wenig (1993) suggested seven ways to infuse choices into instructional activities:

1. Choosing within an activity

2. Choosing between two or more activities

3. Deciding when to do an activity

4. Selecting the person with whom to participate in an activity 
5. Deciding where to do an activity

6. Refusing to participate in a planned activity

7. Choosing to end an activity at a self-selected time.

\section{Problem-Solving}

A problem is "a task whose solution is not immediately perceived" (Beyth-Marom, Fischhoff, Jacobs, Quadrel, \& Furby, 1991). More specifically, a problem is "a situation or set of situations to which a person must respond to function effectively in his environment" (D'Zurilla \& Goldfried, 1971). Problem-solving skills typically have focused on problem resolution in two domains: impersonal problemsolving and interpersonal or social problem-solving. Social problem-solving emphasizes cognitive and behavioral strategies that enable individuals to interact with one another and to cope in an increasingly social world. Much of the focus for intervention in special education has been strictly on social skills training. Although this instruction is important, in the absence of similar emphasis on social problemsolving skills, social skills training alone is not enough to address deficits in social interactions exhibited by youth and adults with disabilities (Chadsey-Rusch, 1986; Park \& Gaylord-Ross, 1989; Wehmeyer \& Kelchner, 1994).

Instruction in problem solving typically includes three focal points:

1. Problem identification

2. Problem explication and analysis

3. Problem resolution.

Instruction should take place within environments that emphasize the student's capability to solve problems, promote open inquiry and exploration, and encourage generalization. Teachers should serve as role models by verbalizing the problem-solving steps used on a day-to-day basis and should make sure that students are provided adequate support and accommodations.

\section{Decision-Making}

Making a decision is a process of selecting or coming to a conclusion about which solution is best given one's circumstances, values, priorities, and needs. Beyth-Marom et al. (1991, p. 21) suggested that most models of decision making incorporate the following steps:

1. Listing relevant action alternatives

2. Identifying consequences of those actions

3. Assessing the probability of each consequence occurring (if the action were undertaken)

4. Establishing the relative importance (value or utility) of each consequence

5. Integrating these values and probabilities to identify the most attractive course of action.
Baron and Brown (1991) proposed that "deficient decision-making is a serious problem throughout society at large and the problem needs addressing in childhood or adolescence." Students need to learn how to define the issue or problem about which a specific decision is to be made, how to collect information about the specific situation, and to use this information to identify options for consideration. Once these options are clarified, students need to learn to be able to identify and evaluate the consequences and outcomes of actions based on the various options. When those consequences have been detailed, choice-making skills can be applied to select a specific alternative. Finally, students must implement this plan of action.

An underlying assumption that many educators and parents hold is that minors do not have the capacity to make informed choices and decisions. This assumption also is made frequently about individuals with disabilities, so the overwhelming assumption about adolescents with disabilities is that they are incapable of participating in the decision-making process. A number of researchers, however, have suggested that minors are competent at making important decisions.

The belief that minors are incapable of making competent decisions results, in part, from the perception that minors and students with disabilities cannot take into account the degree of risk involved with various options. This assumption, however, is not supported by research in developmental psychology. Grisso and Vierling (1978) reviewed the cognitive and behavioral characteristics of minors in relation to the question of competence to consent to treatment. They concluded that "there is no psychological grounds for maintaining the general legal assumption that minors age 15 and above cannot provide competent consent, taking into account risk-related factors." In fact, those authors contended that there are "circumstances that would justify the sanction of independent consent" by minors between the ages of 11 and 14 .

Similarly, Kaser-Boyd, Adelman, and Taylor (1985) asked students ages 10 to 20 , who were identified as having a learning or behavior problem, to list potential risks and benefits of entering psychoeducational therapy. As expected, there was a relationship between age and effectiveness in this task. Even young students, however, were able to identify relevant concerns appropriate to their situation and their developmental needs.

While choice-making should be emphasized early in a student's educational career, decision-making skills probably are better addressed at the secondary level. BeythMarom and colleagues (1991) suggest that to achieve generalization, decision making and problem solving should be taught in terms of familiar knowledge domains. By this, they refer to the effectiveness of teaching these skills in the 
context of a life-skills or functional education curriculum, with decision-making skills learned by applying the process to real world issues.

Be it choice-making or engaging in independent living behaviors, the real barrier for many people with disabilities is that the needs of the caregiver for absolute assurance of safety often tend to lead to the prohibition of activities that have low-level risks. Certainly, behaviors that lead to a certain injury and those that have a moderate probability for harm should be cause for concern. Most behaviors, however, do not involve that level of risk and students with disabilities can be taught to assess the level of risk, and weigh the consequences of action using an effective decision-making process. In addition, students can be taught safety and health-promotion skills that they need to achieve independent living. These skills might include teaching students basic first-aid and job safety skills, nutrition, diet and medication facts, and the prevention of abuse and disease (Agran, Marchand-Martella, \& Martella, 1994).

\section{Goal Setting and Attainment}

To become the causal agent in his or her life, a person has to learn the skills necessary to plan, set, and achieve goals. Goal-setting theory is built on the underlying assumption that goals are regulators of human action. This is true for educational motivation and achievement. For example, Schunk (1985) found that student involvement in goal setting improved performance on math activities for students with learning disabilities.

Educational efforts to promote goal setting and attainment skills should focus on identifying and enunciating specific goals, developing objectives and tasks to achieve these goals, and taking the actions necessary to achieve a desired outcome. The educational planning and decision-making process revolves around goal setting, implementation, and evaluation. Involving students in this process, across all grades, is a good way to promote goal setting and attainment skills. Teachers and parents can model effective skills such as identifying short- and long-term goals, describing objectives, implementing plans based on these goals and objectives, and reevaluating and refining the plans.

\section{Self-Management Skills}

The definitional framework of self-determined behavior identified these actions as self-regulated. Self-regulated behavior includes self-managing one's life, including selfmonitoring, self-evaluation, self-instruction, and selfreinforcement. Self-monitoring strategies involve teaching students to assess, observe, and record their own behavior. Self-monitoring strategies are used most frequently to improve work-related activities, such as attention to task, task completion, and task accuracy (Hughes, Korinek, \&
Gorman, 1991) and, as such, are important to transitionrelated programs. Self-evaluation activities include the use of systematic strategies to enable students to track and evaluate their progress on educational activities, including goals and objectives. This frequently involves self-recording procedures in which the student graphs, charts, or otherwise documents progress on a goal or objective.

Progress typically is determined through some form of self-observation, during which the student discriminates and records that a given target behavior has occurred, then compares it with a previously determined standard or expected outcome (Agran, 1997). Students can be taught to score worksheets, identify the occurrence of a target behavior, track time intervals for the occurrence or nonoccurrence of a target behavior, and record this information in a graphic or chart format.

A third component of self-regulation is the use of selfreinforcement strategies. Agran (1997) defined selfreinforcement as the self-administration of consequences, either positive or negative, contingent on the occurrence of a target behavior, and suggested that self-reinforcement should have two functions: self-identification of reinforcers and delivery of this reinforcer. Student involvement in the former-identification of reinforcers - can enhance the efficacy of the latter. Self-reinforcement can be more effective than having another person deliver the reinforcer, not the least because self-reinforcement is almost always immediate.

Self-instructional strategies involve teaching students to "provide their own verbal prompts for solving an academic or social problem" (Hughes, Korinke, \& Gorman, 1991). This technique has been used successfully to solve job- and work-related problems (Hughes \& Rusch, 1989) and to teach social skills that are critical to independence (Hughes \& Agran, 1993). In essence, self-instruction strategies move the responsibility for providing verbal prompts and cues from an external source, typically the teacher, to the student.

\section{Self-Advocacy and Leadership Skills}

Self-advocacy skills are skills that individuals need to advocate on their own behalf. "To advocate" means to speak up or defend a cause or person. By definition, then, instruction to promote self-advocacy will focus on two common threads how to advocate and what to advocate. Although elementary-age students can begin to learn basic self-advocacy skills, most instructional emphasis in this area will apply during secondary education. One particularly important area in which students with disabilities should receive instruction involves the education and transition process itself and rights (and responsibilities) within that system. For many students with disabilities, school is a place where they are forced to go to do things that someone else decides for them. It is little wonder that motivation is a problem! 
Students who are approaching transition-age can be taught about their rights under the IDEA and, more specifically, about the purpose and process involved in transition decision making. Other topics that could become the "cause" for which students will need to advocate on their own behalf include the adult services system (disability and general), basic civil and legal rights of citizenship, and specific civil and legal protections available to people with disabilities, such as those under the Americans with Disabilities Act. These instructional efforts necessarily will deal with both rights and responsibilities.

Curricular strategies for the "how to advocate" side of self-advocacy include instructional emphasis on being assertive but not aggressive, how to communicate effectively in one-on-one, small-group, and large-group situations, how to negotiate, compromise, and use persuasion, how to be an effective listener, and how to navigate through systems and bureaucracies. Each of these clearly is closely tied to the acquisition and emergence of other self-determination skills. For example, a reliable understanding of one's strengths and weaknesses is an important component if one is to actually use strategies such as negotiation and compromise to achieve an outcome. Likewise, students need to be able to link such advocacy to specific goals and incorporate it into the problem-solving and decision-making process.

\section{Perceptions of Control and Efficacy}

The final four essential elements of self-determined behavior focus not on skill development but, rather, on the attitudes that enable individuals to act in a psychologically empowered or self-realizing manner. If people are to act in or upon a given situation, they have to believe that they have control over outcomes that are important to their life. People who hold such beliefs have been described as having an internal locus of control. Rotter (1966) defined locus of control as the degree to which a person perceives contingency relationships between his or her actions and outcomes. Internal locus of control has been linked to adaptive outcomes, including positive educational and achievement outcomes and increased time and attention to school-related tasks (Lefcourt, 1976). The locus of control construct for individual's with disabilities has not been extensively explored. The research that does exist suggests that people with disabilities hold perceptions of control that are more external, and thus more maladaptive, than their nondisabled peers.

The role of educators in promoting internal perceptions of control, as well as adaptive efficacy and outcome expectations, positive self-awareness, and realistic self-knowledge, is more complex than just providing adequate instructional experiences. An internal locus of control emerges as children make choices about things they do every day, such as selecting clothing, and as these choices are honored and supported. In addition, an educational program that emphasizes problem solving, choice making, decision making, and goal setting and attainment using student-directed learning activities will provide ample opportunities for students to learn that they have control over reinforcers and outcomes important to them.

Particularly important is to consider the learning environment and to evaluate its effect on student perceptions of control. Teachers who use an overly controlling style, or whose classrooms are rigidly structured, limit their students' development of positive perceptions of control. This does not mean that classrooms must become chaotic; allowing more control is not the same as relinquishing all control and abolishing rules and regulations (Deci \& Chandler, 1986). Instead, classrooms can be structured such that students can perform more actions for themselves, such as obtaining their own instructional materials.

Self-efficacy and efficacy expectations are constructs that Bandura (1977) introduced. Self-efficacy refers to the "conviction that one can successfully execute a behavior required to produce a given outcome" (Bandura, 1977, pp. 193). Efficacy expectations refer to the individual's belief that if a specific behavior is performed, it will lead to an anticipated outcome.

It should be evident that the two are individually necessary, but not sufficient, for goal-directed and self-determined actions. Simply put, a person has to believe that: (a) he or she can perform a behavior needed to achieve a desired outcome, and (b) if that behavior is performed, it will result in the desired outcome. If a person does not believe that he or she can perform a given behavior (independent of the validity of that belief), he or she consequently will not perform that action. A person may believe, however, that he or she is capable of performing a given behavior, but because of past experience, may not believe that a desired outcome will occur even if that behavior is exhibited and, as such, will not perform the action. For example, a student with a disability may not believe that she has the social skills necessary to initiate a conversation with nondisabled peers and will refrain from initiating such actions. On the other hand, that same student may believe she has the skills, but having been ignored in the past, may believe that she will be ignored again and, therefore, refrain from initiating the action.

Like perceptions of control, perceptions of efficacy and expectancy have been linked to academic achievement and persistence at academic activities (Lent, Bron, \& Larken, 1984). Little research has examined the self-efficacy and efficacy expectations of individuals with disabilities. Most of the extant literature in the area of learning disabilities focuses on changing self-efficacy and efficacy expectations through environmental or instructional modifications (Schunk, 1989). Wehmeyer (1994) found that individuals with mental 
retardation held fewer adaptive attributions of efficacy and expectancy than did their nondisabled peers, and that such attributions became less adaptive as the student got older.

\section{Self-Awareness and Self-Knowledge}

For individuals to act in a self-realizing manner, they must have a basic understanding of their strengths, weaknesses, abilities, and limitations, as well as knowledge about how to utilize these unique attributions to beneficially influence their quality of life. Students don't learn what they can or can't do from lectures, role playing, social skills simulations, or any other more traditional teacher-directed instructional activities. They learn, as do all people, through their own interpretation of events and experiences.

This process is not one of pure introspection, however, and does not focus exclusively or even primarily on an understanding of limitations. In many cases, students with disabilities are quite able and more willing to identify what they do poorly than the things they do well. The specter of having a disability, as pictured in disease or deficit models, hovers over any circumstance, and students dwell more on what they are unable to accomplish than what they can achieve. Because special education is essentially remedial in nature, this is not surprising.

\section{INSTRUCTION, ASSESSMENT, AND CURRICULUM ISSUES IN QUALITY OF LIFE}

\section{Quality-of-Life-Related Enhancement Techniques}

One of the biggest challenges in the field of special education is to implement and evaluate quality enhancement techniques that focus on the impact of services and supports on a student's perceived quality of life. Currently, special education services worldwide are implementing quality enhancement techniques that are environmentally based or program based.

\section{Environmentally based enhancement techniques}

Implementation of two concepts related to environmentally based quality enhancement techniques poses challenges and opportunities. One is the belief that an enhanced quality of life is the result of a good match between a person's wants and needs and his or her fulfillment and environments. The importance of these two concepts is supported by data suggesting that reducing the discrepancy between a person and his or her environment increases the person's assessed quality of life (Schalock, Keith, Hoffman, \& Karan, 1989).

Two examples illustrate how one might use environmentally based techniques. One technique involves the assessment of environmental characteristics such as: physical or social integration, age-appropriate interpretations and structures, culture-appropriate interpretations and structures, model coherency, developmental growth orientation, and quality of setting (Felce \& Perry, 1997). The second involves the design of environments that are user-friendly and meet the following criteria (Ferguson, 1997): opportunity for involvement; easy access to the outdoor environment; modifications to stairs, water taps, door knobs; safety (e.g., handrails, safety glass, nonslip walking surfaces); convenience (e.g., orientation aids such as color coding and universal pictographs); accessibility; sensory stimulation (windows, less formal furniture); prosthetics (personal computers, specialized assistive devices, and high-tech environments); and opportunity for choice and control (e.g., lights, temperature, personal space and territory).

\section{Program-Based Enhancement Techniques}

Once the core dimensions of quality of life are identified, it is possible to implement program-based [quality] enhancement techniques that will result in an enhanced perceived quality of life for the student. Examples include:

- Emotional well-being: increased safety, stable and predictable environments, positive feedback

- Interpersonal relations: foster friendships, encourage intimacy, support families

- Material well-being: ownership, possessions, employment

- Personal development: functional, application-oriented education, augmentative technology

- Physical well-being: health care, mobility, wellness, nutrition

- Self-determination: choices, personal control, decisions, personal goals

- Social inclusion: community role, community integration, volunteerism

- Rights: privacy, voting, due process, civic responsibilities

\section{Positive Behavior Supports}

Although most closely related to emotional well-being and the program-based enhancement techniques listed above (related to "emotional well-being"), educators are using positive behavior supports increasingly to enhance both positive behavioral change and positive outcomes in students who have problem behaviors. As discussed by Horner (2000), positive behavior support involves focusing on the assessment and reengineering of environments so that students "with problem behaviors experience reductions in their problem behaviors and increased social, personal, and professional quality in their lives" (p. 181).

The technology of positive behavior support applies basic laws of behavior analysis to produce broad changes in the educational environment and options available to students in special education who exhibit problem behaviors. 
Underlying this technology are three key implementation concepts for students with disabilities who exhibit behavior problems (Horner, 2000, pp. 183-184):

1. Behavior support should reduce problem behaviors and affect how a person lives.

2. Functional assessment is the foundation for understanding patterns of problem behavior.

3. Behavior support should be comprehensive in structure and scope.

\section{Persons With Disabilities Assessing Their Quality of Life}

One of the changes over the last two decades is the development of a strong self-advocacy movement in which persons with disabilities are advocating for more opportunities to participate in the mainstream of life. The impact of this change is obvious to most readers who are aware of consumers advocating for increased inclusion and individual supports within regular environments. What might be less obvious is the increasing role that consumers are playing in assessment and evaluation activities. To this end, there is every indication that we will continue to see the emergence and further development of what typically is referred to as "participatory action research," defined as

\footnotetext{
an emerging approach to problem solving and social change that is particularly suited to issues of quality of life.... [It is] described as the sine qua non when studying subjective outcomes. . . . PAR relies on the involvement of stakeholders who can either identify subjective elements of their own lives that warrant change or understand the social contexts in which change occurs. Individuals...can contribute to our collective understanding of how quality of life can be conceptualized, what a life of quality looks like, and ways to improve outcomes. (Whitney-Thomas, 1997, p. 181)
}

Participatory action research is rapidly becoming the method of choice among quality-of-life researchers. For example, consumers are working jointly with researchers to determine the importance of the core quality-of-life dimensions. Preliminary work suggests that for children and youth, the most important dimensions might be personal development, self-determination, interpersonal relationships, and social inclusion (Schalock, 1996b; Stark \& Goldsbury, 1990); for adults, the most important dimensions may well be emotional well-being, material well-being, and interpersonal relations (Elorriaga, Garcia, Martinez, \& Unamunzaga, 2000; Verdugo, 2000); and for the elderly, physical well-being, interpersonal relationships, and emotional wellbeing could be the most important dimensions (Schalock, DeVries, \& Lebsack, 1999).

Consumers also are involved in assessing their own quality of life. For example, we (Schalock et al., 2000) have shown that consumers are excellent surveyors and can assess other consumers' quality of life with highly acceptable reliability and validity. By adapting survey techniques and the language used in the survey, $81 \%$ of consumers were able to respond for themselves, despite having significant cognitive, physical, and language limitations.

Two significant findings came of these studies. First, among the 50 questions asked in the survey, more than three-fifths of the consumers gave the most positive response to eight questions: have transportation, feel safe in neighborhood, staff help with community integration, get needed services, help with goals, feel part of family, concern with health, and people help you learn. Seven questions received the most negative response by the majority of the respondents: what others expect, have a key to home, dating opportunities, number of groups I belong to, who decides on how I spend my money, housemate choice, and have a job.

Second, a path analysis of the results indicated that two areas of subjective well-being contribute directly to satisfaction with life. The most important of the two is dignity (the more dignity with which consumers feel people treat them, the more satisfied they are with life). The second is their work life (the greater the quality of their work life, the more satisfied they are with life overall).

The path analysis also indicated that the degree of independence consumers feel and their integration into the community do not directly affect measured satisfaction, and that these two variables affect satisfaction only indirectly as they affect dignity and work. Further, the path analysis indicated that consumer abilities, as measured by intelligence tests, have no direct effect on life satisfaction, and characteristics such as age, communication problems, and ambulating difficulties have no effect, either directly or indirectly, on life satisfaction.

\section{CONCLUSIONS}

We believe that an emphasis on promoting self-determination and quality of life will provide an entry point for discussions concerning the integration of special education with general education. State and local standards and the curricula derived from these standards emphasize, across elementary, middle, and secondary school ages, instructional experiences pertaining to goal setting, problem solving, decision making and other self-determination-related components. The presence of such standards illustrates the universality of need for instruction in self-determination for all students.

In turn, as the educational programs of all students focus on promoting and enhancing self-determination, it will become more and more important that educational programs, school reform efforts, and accountability systems 
attend to a student's quality of life as an outcome which is specifically targeted and for which systems become accountable. A focus on self-determination leads inevitably to the need to consider personal and personally valued outcomes for students, and to move beyond accountability systems that rely solely on normative outcomes (via testing) or process indicators (e.g., compliance with IEP mandates in IDEA).

\section{REFERENCES}

Agran, M. (1997). Student-directed learning: Teaching self-determination skills. Pacific Grove, CA: Brooks/Cole.

Agran, M., Marchand-Martella, N.E., \& Martella, R.C. (1994). Promoting health and safety: Skills for independent living. Baltimore: Paul H. Brookes.

Agran, M., Snow, K., \& Swaner, J. (1999). Teacher perceptions of selfdetermination: Benefits, characteristics, strategies. Education \& Training in Mental Retardation \& Developmental Disabilities, 34, 293-301.

Bandura, A. B. (1977). Self-efficacy: Toward a unifying theory of behavioral change. Psychological Review, 84, 191-215.

Baron, J. \& Brown, R.V. (1991). Introduction. In J. Baron \& R.V. Brown (Eds.), Teaching decision making to adolescents. Hillsdale, NJ: Lawrence Erlbaum Associates.

Beyth-Marom, R., Fischhoff, B., Jacobs Quadrel, M., \& Furby, L. (1991). Teaching decision-making to adolescents: A critical review. In J. Baron \& R.V. Brown (Eds.), Teaching decision making to adolescents. Hillsdale, NJ: Lawrence Erlbaum Associates.

Brown, F. Appel, C., Corsi, L. \& Wenig, B. (1993). Choice diversity for people with severe disabilities. Education \& Training in Mental Retardation, 28, 318-326.

Chadsey-Rusch, J. (1986). Identifying and teaching valued social behaviors. In F.R. Rusch (Ed.), Competitive employment: Service delivery models, methods and issues (pp. 273-287). Baltimore: Paul H. Brookes.

Chadsey-Rusch, J., Rusch, F., \& O'Reilly, M.F. (1991). Transition from school to integrated communities. Remedial \& Special Education, 12, 23-33.

Committee on Appropriate Test Use. (1999). High stakes. Washington, DC: National Research Council.

Committee on Goals 2000 and the Inclusion of Students with Disabilities (1997). Educating one and all: Students with disabilities and standards-based reform. Washington, DC: National Academy Press.

Council on Quality and Leadership in Supports for People with Disabilities (1997). Personal outcome measures. Towson, MD: Author.

Cummins, R. A. (1997). Assessing quality of life. In R. I. Brown (Ed.), Quality of life for people with disabilities: Models, research and practice (pp. 116-150). Cheltenham, UK: Stanley Thornes (Publishers) Ltd.

Deci, E.L. \& Chandler, C.L. (1986). The importance of motivation for the future of the LD field. Journal of Learning Disabilities, 19, 587-594.

Doll, B., Sands, D.J., Wehmeyer, M.L., \& Palmer, S. (1996). Promoting the development and acquisition of self-determined behavior. In D.J. Sands \& M.L. Wehmeyer (Eds.), Self-determination across the life span: Independence and choice for people with disabilities (pp. 63-88). Baltimore: Paul H. Brookes.

D'Zurilla, T. J.. \& Goldfried, M. R. (1971). Problem-solving and behavior modification. Journal of Abnormal Psychology, 78, 107-126.

Elorriaga, J., Garcia, L., Martinez, J. \& Unamunzaga, E. (2000). Quality of life of persons with mental retardation in Spain. In K.D. Keith \& R. L. Schalock (Eds.), Cross-cultural perspectives on quality of life. Washington, DC: American Association on Mental Retardation.

Felce, D. (1997). Defining and applying the concept of quality of life. Journal of Intellectual Disability Research, 41 (2), 126-135.

Felce, D. \& Perry, J. (1997). A PASS 3 evaluation of community residences in Wales. Mental Retardation, 35(3), 170-176.

Ferguson, R. V. (1997). Environmental design and quality of life. In R. I. Brown (Ed.), Quality of life for people with disabilities: Models, research and practice (pp. 56-70). Cheltenham, UK: Stanley Thornes (Publishers) Ltd.

Field, S. (1996). Self-determination instructional strategies for youth with learning disabilities. Journal of Learning Disabilities, 29, 40-52.

Field, S., Martin, J.E., Miller, R., Ward, M., \& Wehmeyer, M.L. (1998). A practical guide to teaching self-determination. Reston, VA: Council for Exceptional Children.

Grisso, T., \& Vierling, L. (1978). Minor's consent to treatment: A developmental perspective. Professional Psychology, 9, 412-427.

Halpern, A. (1985). Transition: A look at the foundations. Exceptional Children, 51, 479-486.

Halpern, A. (1993). Quality of life as a conceptual framework for evaluating transition outcomes. Exceptional Children, 59, 486-498.

Hatton, C. (1998). Whose quality of life is it anyway? Some problems with the emerging quality of life consensus. Mental Retardation, 36(2), 104-115.

Horner, R. H. (2000). Positive behavior supports. In M. Wehmeyer \& J. R. Patton (Eds.), Mental retardation in the 21st century (pp. 181-196).

Hughes, C., \& Agran, M. (1993). Teaching persons with severe disabilities to use self-instruction in community settings: An analysis of applications. Journal of the Association for Persons with Severe Handicaps, $18,261-274$.

Hughes, C. A., Korinek, L., \& Gorman, J. (1991). Self-management for students with mental retardation in public school settings: A research review. Education \& Training in Mental Retardation, 26, 271-291.

Hughes, C., \& Hwang, B. (1996). Attempts to conceptualize and measure quality of life. In R. L. Schalock (Ed.), Quality of life: Vol. 1. Conceptualization and measurement (pp. 51-62). Washington, DC: American Association on Mental Retardation.

Hughes, C., \& Rusch, F.R. (1989). Teaching supported employees with severe mental retardation to solve problems. Journal of Applied Behavior Analysis, 22, 365-372.

Kaser-Boyd, N., Adelman, H.S., \& Taylor, L. (1985). Minors' ability to identify risks and benefits of therapy. Professional Psychology: Research \& Practice, 16, 411-417.

Keith, K. D., \& Schalock, R. L. (1994). The measurement of quality of life in adolescents: The Quality of Student Life Questionnaire. American Journal of Family Therapy, 22(1), 83-87.

Keith, K. D., \& Schalock, R. L. (1995). Quality of student life questionnaire. Worthington, $\mathrm{OH}$ : IDS Publishing.

Lefcourt, H. M. (1976). Locus of control. Hillsdale, NJ: Lawrence Erlbaum.

Lent, R. W., Bron, S. D., \& Larkin, K. C. (1984). Relationship of self-efficacy expectations to academic achievement and persistence. Journal of Counseling Psychology, 31, 356-362.

Martin, J. E., \& Marshall, L.H. (1995). ChoiceMaker: A comprehensive self-determination transition program. Intervention in School \& Clinic, $30,147-156$.

Martin, J. E., Marshall, L. H., Maxson, L., \& Jerman, P. (1993). Selfdirected IEP: Teacher's manual. Colorado Springs: University of Colorado at Colorado Springs, Center for Educational Research.

Morningstar, M. E., Kleinhammer-Tramill, J., \& Lattin, D. (1999). Using successful models of student-centered transition planning and services for adolescents with disabilities. Focus on Exceptional Children, 31(9), 1-19.

Park, H. S., \& Gaylord-Ross, R. (1989). A problem-solving approach to social skills training in employment settings with mentally retarded youth. Journal of Applied Behavior Analysis, 22, 373-380.

Parmenter, T, \& Donelly, M. (1997). An analysis of the dimensions of quality of life. In R. I. Brown (Ed.), Quality of life for people with disabilities: Models, research and practice (pp. 91-114). Cheltenham, UK: Stanley Thornes (Publishers) Ltd.

Pulliam, J. D., \& Van Patten, J. (1995). History of education in America (6th ed.). Englewood Cliffs, NJ: Merrill-Prentice Hall.

Renwick, R., \& Brown, I. (1996). The Centre for Health Promotion's conceptual approach to quality of life. In R. Renwick, I. Brown, \& M. Nagler (Eds.), Quality of life in health promotion and rehabilitation: Conceptual approaches, issues, and applications (pp. 75-86). Thousand Oaks, CA: Sage Publications. 
Rotter, J. B. (1966). Generalized expectancies for internal versus external control of reinforcement. Psychological Monographs, 80, (1, Whole No. 609)

Schalock, R. L. (1994). Quality of life, quality enhancement, and quality assurance: Implications for program planning and evaluation in the field of mental retardation and developmental disabilities. Evaluation \& Program Planning, 17, 121-131.

Schalock, R. L. (1995). Outcome-based evaluation: New York: Plenum Press.

Schalock, R. L. (1996a). Reconsidering the conceptualization and measurement of quality of life. In R. L. Schalock (Ed.), Quality of life: Vol. 1. Conceptualization and measurement. Washington, DC: American Association on Mental Retardation.

Schalock, R. L. (1996b). The quality of children's lives. In A. H. Fine \& N. M. Fine (Eds.), Therapeutic recreation for exceptional children: Let me in, I want to play (2d ed.) (pp. 83-94). Springfield, IL: Charles C. Thomas Publishers, Ltd.

Schalock, R. L. (2000). Three decades of quality of life. In M. Wehmeyer \& J. R. Patton (Eds.), Mental retardation in the 21st century (pp. 335-358). Austin: Pro-Ed Publishers.

Schalock, R. L. (in press). Outcome-based evaluation, 2d ed. New York: Kluwer Academic/Plenum Publishers.

Schalock, R. L., Bonham, G., \& Marchand, C. (2000). Consumer based quality of life assessment: A path model of perceived satisfaction. Evaluation \& Program Planning, 23, 77-87.

Schalock, R. L., DeVries, D. \& Lebsack, J. (1999). Rights, quality measures, and program changes. In S. S. Herr \& G. Weber (Eds.), Aging, rights and quality of life: Prospects for older persons with developmental disabilities (pp. 81-92). Baltimore: Paul H. Brookes.

Schalock, R. L. \& Faulkner, E. H. (1997). Cross-validation of a contextual model of quality of life. European Journal on Mental Disability, 4(1), $18-27$.

Schalock, R. L., Keith, K.A., Hoffman, K. \& Karan, O.C. (1989). Quality of life: Its measurement and use. Mental Retardation, 27(1), 25-31.

Schalock, R. L., Lemanowicz, J. A. Conroy, J. W., \& Feinstein, C. S. (1994). A multivariate investigative study of the correlates of quality of life. Journal on Developmental Disabilities, 3(2), 59-73.

Schunk, D. H. (1985). Participation in goal setting: Effects on self-efficacy and skills of learning disabled children. Journal of Special Education, $19,307-316$

Schunk, D. H. (1989). Social cognitive theory and self-regulated learning. In B. J. Zimmerman \& D. H. Schunk (Eds.), Self-regulated learning and academic achievement: Theory, research and practice. New York: Springer-Verlag.

Shevin, M., \& Klein, N.K. (1984). The importance of choice-making skills for students with severe disabilities. Journal of the Association for Persons with Severe Handicaps, 9, 159-166.

Sigafoos, A. D., Feinstein, C. B., Damond, M., \& Reiss, D. (1988). The measurement of behavioral autonomy in adolescence: The Autonomous Functioning Checklist, in C. B. Feinstein, A. Esman, J. Looney, G. Orvin, J. Schimel, A. Schwartzberg, A. Sorsky, \& M. Sugar (Eds.), Adolescent Psychiatry (Vol. 15, pp. 432-462). Chicago: University of Chicago Press.

Sitlington, P. L. (1996). Transition to living: The neglected component of transition programming for individuals with learning disabilities. Journal of Learning Disabilities, 29, 31-39.

Stark, J. A. \& Goldsbury, T. (1990). Quality of life from childhood to adulthood. In R. L. Schalock (Ed.), Quality of life: Perspectives and issues (pp. 71-84). Washington, DC: American Association on Mental Retardation.

Sykes, G., \& Plastrik, P. (1993). Standards setting as educational reform (ERIC Clearinghouse on Teacher Education, Trends and Issues Paper, No. 8). Washington, DC: American Association of Colleges for Teacher Education.

Verdugo, M. A. (2000). Quality of life for persons with mental retardation and developmental disabilities in Spain: The present zeitgeist. In K. D. Keith \& R. L. Schalock (Eds.), Cross-cultural perspectives on quality of life. Washington, DC: American Association on Mental Retardation.
Ward, M. J. (1996). Coming of age in the age of self-determination: A historical and personal perspective. In D. J. Sands \& M. L. Wehmeyer (Eds.), Self-determination across the life span: Independence and choice for people with disabilities (pp. 1-14). Baltimore: Paul H. Brookes.

Ward, M.J., \& Kohler, P.D. (1996). Promoting self-determination for individuals with disabilities: Content and process. In L.E. Powers, G.H.S Singer, \& J. Sowers (Eds.), On the road to autonomy: Promoting selfcompetence in children and youth with disabilities (pp. 275-290). Baltimore: Paul H. Brookes.

Wehmeyer, M. L. (1994). Perceptions of self-determination and psychological empowerment of adolescents with mental retardation. Education \& Training in Mental Retardation \& Developmental Disability, 29, 9-21.

Wehmeyer, M. L. (1996). Self-determination as an educational outcome: Why is it important to children, youth and adults with disabilities? In D. J. Sands \& M. L. Wehmeyer (Eds.), Self-determination across the life span: Independence and choice for people with disabilities ( $\mathrm{pp}$. 15-34). Baltimore: Paul H. Brookes.

Wehmeyer, M. L. (1998). Self-determination and individuals with significant disabilities: Examining meanings and misinterpretations. Journal of the Association for Persons with Severe Handicaps, 23, 5-16.

Wehmeyer, M. L., Agran, M., \& Hughes, C. (1998). Teaching self-determination to students with disabilities: Basic skills for successful transition. Baltimore: Paul H. Brookes.

Wehmeyer, M. L., Agran, M., \& Hughes, C. (2000). A national survey of teacher's promotion of self-determination and student-directed learning. Journal of Special Education, 34, 58-68.

Wehmeyer, M. L., \& Kelchner, K. (1994). Interpersonal cognitive problemsolving skills of individuals with mental retardation. Education \& Training in Mental Retardation, 29, 265-278.

Wehmeyer, M. L., Kelchner, K., \& Richards, S. (1995). Individual and environmental factors related to the self-determination of adults with mental retardation. Journal of Vocational Rehabilitation, 5, 291-305.

Wehmeyer, M. L., Kelchner, K., \& Richards. S. (1996). Essential characteristics of self-determined behaviors of adults with mental retardation and developmental disabilities. American Journal on Mental Retardation, 100, 632-642.

Wehmeyer, M. L., Lattin, D., \& Agran, M. (in press). Achieving access to the general curriculum for students with mental retardation. Education and Training in Mental Retardation and Developmental Disabilities.

Wehmeyer, M. L., \& Sands, D. J. (1998). Making it happen: Student involvement in education planning, decision-making and implementation. Baltimore: Paul H. Brookes.

Wehmeyer, M. L., \& Schwartz, M. (1997). Self-determination and positive adult outcomes: A follow-up study of youth with mental retardation or learning disabilities. Exceptional Children, 63, 245-255.

Wehmeyer, M. L., \& Schwartz, M. (1998). The self-determination focus of transition goals for students with mental retardation. Career Development for Exceptional Individuals, 21, 75-86.

Wehmeyer, M. L. \& Schwartz, M. (1998b). The relationship between selfdetermination, quality of life, and life satisfaction for adults with mental retardation. Education \& Training in Mental Retardation \& Developmental Disabilities, 33, 3-12.

Whitman, T. L. (1990). Self-regulation and mental retardation. American Journal on Mental Retardation, 94, 347-362.

Whitney-Thomas, J. (1997). Participatory action research as an approach to enhancing quality of life for individuals with disabilities. In R. L. Schalock (Ed.), Quality of life: Vol. 2. Application to persons with disabilities (pp. 181-198). Washington, DC: American Association on Mental Retardation.

Zimmerman, M. A. (1990). Toward a theory of learned hopefulness: A structural model analysis of participation and empowerment. Journal of Research in Personality, 24, 71-86. 